\title{
Sustainable Development Measures to Respond Climate Change for Valley City Lanzhou Based on Urban Planning Perspective
}

\author{
Xinhong Zhang ${ }^{1,2}$ a \\ ${ }^{1}$ College of Resources and Environment, University of Chinese Academy of Sciences, Beijing, \\ 100049, China \\ ${ }^{2}$ Department of Urban Planning, Lanzhou University of Technology, Lanzhou, 730050, China \\ aemail: jiaochen964@126.com
}

Keywords: Sustainable Development; Urban planning; Climate change; Valley City; Lanzhou City

\begin{abstract}
Global climate change has brought out severe challenges to sustainable development of Lanzhou city which is a valley city. Based on urban planning perspective, the paper studied its sustainable development measures to respond climate change from integrated considerations of "retarding" and "adapting". The results demonstrate: in the first place, it should create new planning method to commonly retard and adapt climate change through pouring attention to the low-carbon planning method and negative planning method. In the second place, it should rationally ascertain its capacity and growth boundary to reduce the exposure degree and vulnerability, and explore new land-use mode to enhance the capability of responding climate change through distributing different lands scientifically. The last but not the least, it should reconstruct the urban spatial form to protect carbon sink space and defending disaster greenbelt on city scale, and consequently develop newtype community whose living function and production function are multiple, in addition, it's a "defending disaster community" whose safety facilities are complete and disaster-prevention space organization is orderly.
\end{abstract}

\section{Introduction}

In May 2007, Brigitte Leoni, who is the spokesman of International Strategy for Disaster Reduction (ISDR) of United Nations, pointed out that climate change and urbanization are the two major factors that make human beings more vulnerable to disasters [1]. The climate change has become a major factor that influences the way of people living and production after urbanization [2]. The impact of climate change on regional environment, not only makes human beings more exposed to those serious threats of a variety of natural disasters, but also profoundly restricts the sustainable development of Chinese economy and society, especially to valley cities whose natural geographical environment are complex and very sensitive to climate change, and the occurrence of natural disaster is more frequent. Lanzhou is a typical valley city in the Northwest China. It's in a rapid developing stage of urbanization and confronting several severe problems, such as natural disasters threaten is serious, industry energy consumption is high, and difficulties of transferring growth mode are more. However, it has become a strategic issue to sustainable development of Lanzhou city for how to control the adverse effect caused by urbanization development and actively respond to the impact produced by climate change.

As a technology and public policy to achieve sustainable development through effectively allocating spatial resource, urban planning possesses favorable properties such as forward-looking, broader thinking and comprehensiveness, and plays a significant role in responding global climate change. In response, on the basis of analyzing the climate change impacts to Lanzhou city, the paper aims at discussing the objective and urgent practicing proposition about exploring the sustainable development measures on the aspects of innovating the planning method, land-use mode and spatial form organization. 


\section{The status of Lanzhou city}

Acting as a provincial capital, Lanzhou city is the political, economic, and cultural center of Gansu province, and has three appellations, which are "Terrestrial Capital”, "Silk Road City" and "Yellow River Capital”. As the "Terrestrial Capital”, it's the geometric center of Chinese inland, located in the convergence zone of Qinghai-Tibet Plateau, Mongolia Plateau and Loess Plateau, its geological structure is complex, ecological environment is fragile, and natural disaster threat is serious [3]. As a "Silk Road City", it's a significant transportation junction in the Northwest China and a first-level node city on Silk Road Economic Belt, the Longhai, Lanxin, Lanqing and Baolan four railways are meeting here. Because of locating in the center of northwest area, it is critical to the security and stability of northwestern region even the entire western frontier, and so it's the strategic region for guaranteeing the national security and ethnic unity [4]. As the "Yellow River Capital”, it situates the Yellow River upper stream and seats in several valley basins whose scale are different, and the surrounding mountains which called North Mountains and South Mountains are closely confronting. Lanzhou city is a typical strip and group valley city, its space is narrow and integrity is low [5], the area of city district is about $230 \mathrm{~km}^{2}$. According to government census statistics in 2014, its gross domestic product (GDP) achieved 190.52 billion RMB and population is about 2.54 million in city district.

\section{The main impacts of climate change on Lanzhou City}

\section{The natural disasters threats would become serious}

Owing to the complex terrain, geological and meteorological conditions, the ecological environment of Lanzhou city is very fragile, lack of rain and short of water [3]. In the long term, Lanzhou confronts serious threats of floods, debris flows, landslides and other natural disasters [6], and the imbalance of seasonal precipitation caused by climate change would aggravate these threats. With the increase of the frequency of strong rainfall, it's easier to induce and aggravate soil erosion, landslide, collapse, debris flow disasters, and threat to urban infrastructure, housing, production activity and security, especially to the poverty settlements such as Chenguanying, Xintan and Beitan that are adjacent to drainage ditches (Fig.1). On the other hand, the persistent drought would increase the possibility of severe drought disaster, which cause the loss of reservoirs and rivers, the water consumption of industry and living would become shortage.

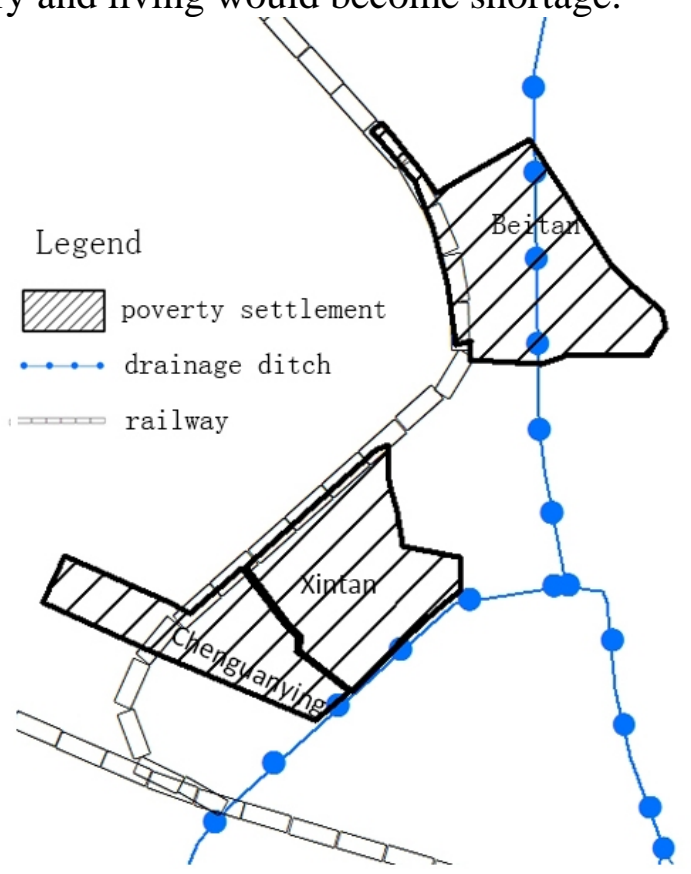

Fig.1 The poverty settlements which are adjacent to drainage ditches

Urban heat island (UHI) effect would become severe

Because the urbanization of Lanzhou city have obtained rapid advance since the Western 
Development Strategy implemented, the UHI effect strengthened increasingly. The studies demonstrate that annual average temperatures in Lanzhou city is higher 3 4 ${ }^{\circ}$ than the three suburban counties, which are Gaolan, Yuzhong and Yongdeng, and the UHI effect intensity is greater in summer [7], and the UHI average intensity was increased in the past thirty years (Table.1). With the aggravation of UHI effect, the frequency and intensity of high temperature, heat wave and drought would increase, the electricity load and energy consumption would increase, and so the carbon emission would increase sharply. Meanwhile, due to it seats in the valley basin whose geographical environment is enclosed, the aggravation of UHI effect would intensify the accumulation of smog, smoke, harmful gases and dust in the air over Lanzhou city, and would format serious air pollution.

Tab.1 The UHI average intensity in the past thirty years

\begin{tabular}{|c|c|c|c|}
\hline Time & $\begin{array}{c}\text { Average } \\
\text { temperature }\end{array}$ & $\begin{array}{c}\text { Minimum } \\
\text { air temperature }\end{array}$ & $\begin{array}{c}\text { Maximum } \\
\text { air temperature }\end{array}$ \\
\hline $1980 \mathrm{~s}$ & 0.93 & 1.33 & 0.70 \\
\hline $1990 \mathrm{~s}$ & 1.43 & 2.22 & 0.87 \\
\hline $2000 \mathrm{~s}$ & 1.47 & 2.26 & 0.80 \\
\hline
\end{tabular}

The transformation of economic growth would encounter more difficulties

The present industry growth mode of Lanzhou city still belongs to the resource-driven type. The heavy industrial structure, constituted by petrochemical industry, metallurgical industry, electric power industry and building materials industry (Table.2), had caused the energy consumption level of GDP couldn't reduce substantially in a long time, and the characteristic of high carbon economy is remarkable now. Under the background of climate change, low carbon competitiveness has become a measuring method of sustainable development capability to cities. Changing the growth mode, taking the low-carbon growth path of saving energy and reducing emission have become the only way to improve the low carbon competitiveness for Lanzhou city. However, this would increase more difficulties, because it's in the key stage of industrialization and experiencing the international and domestic industry transfer.

Tab.2 Enterprise number and production value of several heavy industries in 2013

\begin{tabular}{|c|l|c|c|c|c|}
\hline \multicolumn{2}{|c|}{ Industry } & Petrochemical & Metallurgical & Electric power & Building materials \\
\hline \multirow{2}{*}{$\begin{array}{c}\text { Enterprise } \\
\text { Number }\end{array}$} & Sum & 55 & 50 & 16 & 59 \\
\cline { 2 - 6 } & Proportion (\%) & 14.10 & 12.82 & 4.10 & 15.13 \\
\hline $\begin{array}{c}\text { Production } \\
\text { Value }\end{array}$ & Sum(billion RMB) & 90.01 & 37.89 & 27.24 & 16.27 \\
\cline { 2 - 6 } & Proportion (\%) & 37.25 & 15.68 & 11.27 & 6.74 \\
\hline
\end{tabular}

\section{Sustainable development measures from urban planning perspective}

\section{Create new urban planning method}

"Retarding" and "adapting" are the two indispensable measures to respond global climate change, and also indispensable for urban planning [8]. "Low carbon urban planning" as a method to achieve the goal of low carbon development model, it could play a role in reducing the carbon footprint through a variety of techniques and approaches $[9,10]$. However, from the perspective of comprehensive response to climate change, low carbon urban planning is one-sided and insufficient, because it has mainly played the "retarding" role. Consequently, the city should seek new methods to improve the "adapting" capability in urban planning of responding climate change. The "negative planning" is a beneficial method to plan urban space through firstly controlling the unconstructed region [11,12], it provides helpful reference to adapting climate change. It suggests that urban spatial distribution should take protecting ecological service function as premise, and construct ecological infrastructure to recover ecological service function of land system and enhance the capability and immunity of preventing natural disasters. Therefore, it is necessary for valley city Lanzhou to commonly integrate these two methods and innovate new planning method, which is giving consideration to retard and adapt climate change, and meets the needs of "reduce carbon" 
and "defend disaster " in urban planning at the new stage

\section{Innovate the urban land-use mode}

The developing space and capacity of Lanzhou city is limited, excessive aggregation of population and industries would bring about hidden troubles to its sustainable development. To positively respond the adverse impact of climate change, the city should rationally ascertain its capacity and growth boundary on the basis of evaluating disaster risks and developing suitability. From two-dimensional perspective, in order to use land resource sustainably and safely, the city should reduce to nibble at the carbon sink space such as agricultural land and forest land that are distributed around Anning district and Qilihe district, and prohibit from exploiting the geological hazard prone areas which are in river valley or under the piedmont. From three-dimensional perspective, in order to reduce exposure degree and vulnerability, it should restrict the land-use intensity and control population density and property density.

Rational land-use structure is contributed to reducing the carbon footprint of human activities, and also lowering the frequency of natural disasters and their losses. For valley city Lanzhou, innovating land-use mode is the first choice in urban planning to reduce the carbon footprint and improve the capability of defending disaster. Specifically, the city should take the space requirements of reducing carbon footprint and defending disasters as the essential starting point for the optimal allocation of land-use structure, and seek new land-use mode to balance the social economic benefit and ecological benefit of urban land-use in scientific way by employing the advanced technology such as GIS, cellular automation and multi-agent system.

\section{Reconstruct the urban spatial form}

On city district scale, the city should construct an alternative distributed pattern constituted of core groups and ecological greenbelts, and make the core groups locate between the outer mountainous region and the inner ecological green land. Although this kind of spatial form organization would lower the compactness of Lanzhou city, it's significant to protect the ecological infrastructure and carbon sink space, and create significant conditions to construct a series of multifunction groups and smart-growth groups. Further, in order to reduce the huge increasing of traffic demand caused by the separation among groups and lower energy consumption and carbon footprint from the source consequently, the construction of core groups should abandon the practice of function division, let each groups has a variety of producing functions, living functions, suitable developing density and higher compactness.

Compared with the zoning system based on the principle of land rent, the Danwei community is an advanced mode of spatial form organization for cities; it possess prominent advantages on the aspects of energy consumption, living quality and community's sustainable development [13]. However, it has practicing significance for responding climate change on community scale. Nowadays, there are several Danwei communities in Lanzhou city that handed down from the planned economy period; they should be saved by constructing infrastructure and improving their human settlements. For the new and awaiting construction community, it should improve the accessibility of public transportation, business and employment opportunity by urban planning guidance, and gradually achieve the goal of community's functions are mixed and the distance between residence and working place is adjacent. Furthermore, on the space layout, infrastructure construction and management model, the communities should consider the requirements of defending disaster, and construct themselves as "defending disaster community", especially for the poverty communities, whose safety facilities are complete and disaster-prevention space organization is orderly.

\section{Summary}

Based on the urban planning perspective, the paper studied sustainable development measures to respond climate change for Lanzhou City. The results demonstrate: in the first place, it should create new planning method to commonly retard and adapt climate change through pouring attention to the low-carbon planning method and negative planning method. In the second place, it should rationally ascertain its capacity and growth boundary to reduce the exposure degree and vulnerability, and 
explore new land-use mode to enhance the capability of responding climate change through distributing different lands scientifically. The last but not the least, it should reconstruct the urban spatial form to protect carbon sink space and defending disaster greenbelt on city scale, and consequently develop new-type community whose living function and production function are multiple, in addition, it's a "defending disaster community" whose safety facilities are complete and disaster-prevention space organization is orderly.

\section{References}

[1] Annual Report on Actions to Address Climate Change (2013): Focus on Low-carbon Urbanization [M].Beijing: Social Sciences Academic Press, 2013:189.

[2] Dong Suo-cheng, Tao Shu, Yang Wang-zhou, etc. The Impacts of Climate Change on Urban Agglomeration in Central and Western Region of China [J].Journal of Arid Land Resources and Environment, 2011, 25(2): 72-77.

[3] Zhang Xin-hong, Lei Chun-fang, Li Hong-fei. Study on Natural Disaster Prevention Countermeasures for Western Valley City from the Perspectiveof City Planning: A Case of Lanzhou City [J]. Applied Mechanics and Materials, 2013, 409-410: 827-832.

[4] Zhang Zhibin, Zhang Xinhong. Rearch on Urban Integration and Coordinated Development of Lanzhou and Xining[J]. Economic Geography, 2006,25(6):1073-1082.

[5] Zhang Zhibin, Zhang Yingya. Northwest Inland City Low-Income People Living Space and Social Effect in Lanzhou City as an Example [J]. Economic Geography, 2015,35(5):78-84.

[6] Bao wen, Cui peng. Urban Development and Mountain Hazards Prevention in Lanzhou City [J]. Journal of Arid Land Resources and Environment, 2008, 22(3): 33-36.

[7] Wei Hai-dong, ZhaoYou-yi, Chen Ying. Grey Assessment and Prediction of the Urban Heat Island Effect in Lanzhou City [J]. Journal of Desert Rearch, 2009, 29(3): 571-575.

[8] Hilda BLANCO, Marina ALBERTI. Building Capacity to Adapt to Climate Change through Planning [J]. Research of Urban and Rural Planning, 2011, (1): 1-22.

[9] Gu Chao-lin, Tan Zong-bo, Liu Wan, et al. A Study on Climate Change, Carbon Emissions and Low-carbon City Planning [J].Urban Planning Forum, 2009, (3): 39-45.

[10] Zhang Quan, Ye Xing-ping, Chen Guo-wei. Low-carbon City Planning: a New Vision[J].Urban Planning, 2010, 34(2): 13-18.

[11] Yu Kong-jian, Li Di-hua, Han Xi-li. On The “Negative planning” [J].Urban Planning, 2005, 29(9): 64-69.

[12] Yu Kong-jian, Li Hai-long, Li Di-hua. The Negative Approach and Ecological Infrastructure: The Smart Preservation of Natural Systems in the Process of Urbanization [J]. Journal OF Natural Resoures, 2008, 23(6): 937-958.

[13] Chai Yan-wei, Zhang yan. Rethinking Danwei Community in Urban China: Actions to Global Climate Changes [J]. The international urban planning, 2010, 25(1): 22-23. 